\title{
Pipeline Embolization for Salvage Treatment of Previously Stented Residual and Recurrent Cerebral Aneurysms
}

\author{
Matthew T. Bender ${ }^{a}$ Chau D. Vo ${ }^{a} \quad B^{\prime}$ owen Jiang ${ }^{a} \quad$ Jessica K. Campos ${ }^{a}$ \\ David A. Zarrin ${ }^{a}$ Risheng $\mathrm{Xu}^{\mathrm{a}}$ Erick M. Westbroek ${ }^{\mathrm{a}}$ Justin M. Caplan ${ }^{\mathrm{a}}$ \\ Judy Huang ${ }^{a}$ Rafael J. Tamargo ${ }^{a}$ Li-Mei Lin ${ }^{b}$ Geoffrey P. Colbyc \\ Alexander L. Coon ${ }^{a}$ \\ a Department of Neurosurgery, Johns Hopkins University School of Medicine, Baltimore, \\ MD, USA; ${ }^{b}$ Department of Neurosurgery, University of California Irvine, Orange, CA, USA; \\ 'Department of Neurosurgery, University of California Los Angeles, Los Angeles, CA, USA
}

\section{Keywords}

Flow diversion $\cdot$ Intracerebral aneurysm $\cdot$ Intracranial stenting $\cdot$ Recanalization $\cdot$ Stents

\begin{abstract}
Introduction: This study assessed the safety and effectiveness of the Pipeline embolization device (PED) for persistent and recurrent aneurysms previously treated with either a vascular reconstruction device (VRD) or a flow diverter (FD). Methods: A prospective, IRB-approved database was analyzed for patients treated with PED for aneurysms previously treated with a stent. Results: Twenty procedures were performed on 18 patients, 11 with prior FD, 7 with VRD, and 2 previously treated with both. Overall, 15 aneurysms were saccular (75\%), and size was $13.5 \pm 7.6 \mathrm{~mm}$. Location was internal carotid artery (ICA) in 14 cases $(70 \%)$ and posterior circulation in 6 cases (30\%). Average prior treatments were 1.7. Previously FD cases were retreated at an average of 18.1 months from most recent treatment. Each case used 1 device, $82 \%$ with distal coverage and $82 \%$ with proximal coverage of prior stent. Balloon remodeling was performed in 3 cases (27\%) and no in-stent thrombosis was observed. Previously VRD stent-coiled cases were re-treated at an average of 87.5 months. These cases used on average 1.9 devices, $89 \%$ with distal and $100 \%$ proximal coverage. Adjunctive coiling was performed in 1 case (11\%), balloon remodeling in 5 cases (56\%), and 2 cases (28\%) developed thrombosis that resolved with abciximab. Re-VRD cases were longer (59.1 vs. $33.7 \mathrm{~min}, p=0.02$ ) than reFD. Angiographic follow-up was available for 16 cases (80\%). In re-FD, occlusion was complete in $56 \%$ and partial progressive in $33 \%$ at 17.1 months digital subtraction angiography. In re-
\end{abstract}


VRD, occlusion was complete in $57 \%$ and partial progressive in $27 \%$ at 8.1 months. Two complications occurred (10\%), including one asymptomatic cervical ICA occlusion and one stent occlusion with associated mortality (5\%). Clinical follow-up was 17.8 months on average (range 0.5-51.9). Conclusions: Salvage flow diversion for previously stented aneurysms is technically challenging but offers good prospects of aneurysm obliteration with acceptable complication rates.

(C) 2018 S. Karger AG, Basel

\section{Introduction}

Stent-coiling with a vascular reconstruction device (VRD) was developed as an alternative to stand-alone coiling or balloon-assisted coiling for large, wide-necked, and fusiform aneurysms. This technique reduces the risk of coil prolapse into the parent vessel and increases packing density, particularly at the aneurysm neck, to improve occlusion rates [1, 2]. The Pipeline embolization device (PED) was approved with a similar indication for large and giant aneurysms of the internal carotid artery (ICA). The PED has low rates of major complication and complete occlusion of $\sim 80 \%$ of aneurysms 1 year after treatment, increasing thereafter [3-5]. Recanalization and recurrence after coiling as well as aneurysm persistence after flow diversion (FD) are a problem in spite of these contemporary technologies [6]. There is a limited reference literature for the use of FD as salvage therapy for aneurysms in this setting [7-9]. This study assesses the safety and effectiveness of the PED as a salvage treatment for persistent and recurrent aneurysms that were previously treated with either VRD or FD.

\section{Methods}

This study was a retrospective cohort from an Institutional Review Board-approved, prospectively collected database of aneurysm patients at a tertiary medical center between February 2012 and September 2017. We included all patients in whom previous stenting of aneurysm had failed to achieve complete occlusion who then underwent PED placement as a salvage therapy. Patient consent was not required, as data are collected in a de-identified manner on routine clinical practice at our institution. PED placement was generally performed as previously described $[10,11]$ through an 8 -Fr femoral sheath and a triaxial system that consisted of a long guide sheath [12], distal access catheter [13], and 0.027" microcatheter [14]. Patients recovered in the neurocritical care unit and were typically discharged home on postprocedure day 1. After discharge, patients were scheduled for clinical and angiographic follow-ups. Aneurysm occlusion at followup was evaluated as complete occlusion, entry remnant, subtotal filling, or total filling [15]. Demographic information, clinical history, and outcomes were collected from medical records. Anatomic and technical details were collected from angiograms and operative reports through September 2017.

Statistical Analysis

Data are presented as means and range for continuous variables and as frequency for categorical variables. Statistical analysis was carried out using $t$ tests and Fisher's exact tests.

\section{Results}

A total of 20 procedures were performed on 18 patients for recurrent aneurysms that had previously undergone stenting. There are 11 cases with prior FD (re-FD), 7 cases with VRD, and 2 cases formerly treated with both (re-VRD). The average number of prior treat- 
Table 1. Demographics and anatomy

$\begin{array}{lc}\text { Total cases } & 20 \\ \text { Total patients } & 18 \\ \text { Age, years } & 57.1 \pm 11.33(37-80) \\ \text { Female sex } & 16(80) \\ \text { Previous treatments } & 1.7(1-4) \\ \quad \text { Clipped } & 1(5) \\ \text { Coiled } & 10(50) \\ \text { VRD } & 9(45) \\ \text { FD } & 13(65) \\ \text { Size, mm } & 13.5 \pm 7.58(2.9-25) \\ \text { Small } & 7(35) \\ \text { Large } & 11(55) \\ \text { Giant } & 2(10) \\ \text { Type } & \\ \text { Saccular } & 15(75) \\ \text { Fusiform } & 2(10) \\ \text { Dissecting } & 3(15) \\ \text { History of SAH } & 4(20)\end{array}$

Data are presented as mean \pm SD (range) or $n(\%)$. VRD, vascular reconstruction device; FD, flow diverter; $\mathrm{SAH}$, subarachnoid hemorrhage.

ments was 1.7 (range 1-4), including clipping (1 case, 5\%) and coiling (10 cases, 50\%) in addition to stenting. The FD used in prior interventions was PED $(n=13)$. Previous VRDs included first-generation nitinol self-expanding stents such as Neuroform (Stryker Neurovascular, Fremont, CA, USA) ( $n=5$ ) and Enterprise (Codman \& Shurtleff, Raynham, MA, USA) $(n=1)$, coronary stent $(n=3)$, and Wallstent (Boston Scientific, Marlborough, MA, USA) $(n=$ 1) (Table 1).

Overall, the average patient age was $57.1 \pm 11.3$ years, and $80 \%$ were female. The average aneurysm size was $13.5 \pm 7.6 \mathrm{~mm}$, and $65 \%$ of aneurysms were $\geq 10 \mathrm{~mm}$ in size. Fifteen aneurysms were saccular (75\%), 2 were fusiform (10\%), and 3 were dissecting (15\%) (Table 1). Four cases (20\%) presented with a history of subarachnoid hemorrhage. A majority of aneurysms originated from the ICA (14 cases, $70 \%)$, and 6 cases (30\%) arose from the posterior circulation. ICA aneurysm locations included cavernous (4 cases, 20\%), clinoidal/paraophthalmic (6 cases, 30\%), and supraclinoidal/posterior communicating artery (4 cases, $20 \%$ ). Posterior circulation aneurysm locations included V4 segment ( 2 cases, $10 \%$ ), posterior inferior cerebellar artery ( 2 cases, $10 \%)$, vertebrobasilar junction (1 case, 5\%), and midbasilar ( 1 case, $5 \%$ ).

Procedural success for PED salvage treatment was achieved in all 20 cases (100\%). PED Classic was utilized in 7 cases (35\%), and PED Flex was used in 13 cases (65\%). Previously FD cases were re-treated at an average of $18.1 \pm 11.4$ months since last treatment for aneurysm persistence, including 2 cases of device foreshortening. Only 1 flow-diverting stent was utilized in each case, $82 \%$ with distal coverage of prior stent, $82 \%$ with proximal coverage, and $55 \%$ with both proximal and distal coverage. Balloon remodeling was performed in 3 cases $(27 \%)$, and no in-stent thrombosis was observed. One case required verapamil infusion (9\%) to resolve vasospasm (Table 2).

Previously VRD stent-coiled cases were re-treated at an average of $87.5 \pm 52.0$ months for recurrence, which is significantly longer than re-FD treatments $(p=0.0002)$. These cases used an average of 1.9 flow-diverting devices (range 1-3), 89\% with distal coverage of prior stent and $100 \%$ with proximal coverage of prior stent. Adjunctive coiling was performed in 1 
Table 2. Procedural details and outcomes

\begin{tabular}{|c|c|c|c|c|}
\hline & re-PED & re-VRD & Total & $p$ value \\
\hline Cases & $11(55)$ & $9(45)$ & 20 & \\
\hline Procedural success & $11(100)$ & $9(100)$ & $20(100)$ & \\
\hline \multirow[t]{2}{*}{ Duration since latest $\mathrm{Tx}$, months } & $18.1 \pm 11.4$ & $87.5 \pm 52$ & $47.3 \pm 48.57$ & 0.0002 \\
\hline & $(3.2-42.6)$ & $(8.3-155.2)$ & $(3.2-155.2)$ & \\
\hline \multicolumn{5}{|l|}{ Access \& catheters } \\
\hline Average \#PED used & $1(1-1)$ & $1.9(1-3)$ & $1.4(1-3)$ & 0.0025 \\
\hline \multicolumn{5}{|l|}{ Coverage } \\
\hline Distal coverage & $9(82)$ & $8(89)$ & $17(85)$ & \\
\hline Proximal coverage & $9(82)$ & $9(100)$ & $18(90)$ & \\
\hline \multicolumn{5}{|l|}{ Case characteristics } \\
\hline \multirow[t]{2}{*}{ Flouro time, min } & $33.7 \pm 16.2$ & $59.1 \pm 31.9$ & $45.1 \pm 27.1$ & 0.02 \\
\hline & $(12.2-62.6)$ & $(22.9-117.8)$ & $(12.2-117.8)$ & \\
\hline \multirow[t]{2}{*}{ Radiation exposure, mGy } & $2,132 \pm 1,061$ & $3,812 \pm 2,551$ & $2,888 \pm 2,017$ & 0.03 \\
\hline & $(1,218-4,797)$ & $(1,274-8572)$ & $(1,218-8572)$ & \\
\hline Adjunct coil deployment & $0(0)$ & $1(11)$ & $1(5)$ & 0.45 \\
\hline Vasospasm (verapamil infusion) & $1(9)$ & $1(11)$ & $2(10)$ & 1.00 \\
\hline Balloon angioplasty & $3(27)$ & $5(56)$ & $8(40)$ & 0.36 \\
\hline PED thrombosis & $0(0)$ & $2(22)$ & $2(10)$ & 0.19 \\
\hline \multicolumn{5}{|l|}{ Aneurysm occlusion } \\
\hline DSA follow-up & $9(82)$ & $7(78)$ & $16(80)$ & 1.00 \\
\hline \multirow[t]{2}{*}{ Time to DSA follow-up, months } & $17.1 \pm 15.8$ & $8.1 \pm 3.1$ & $13.1 \pm 12.5$ & 0.16 \\
\hline & $(5-51.9)$ & $(5.6-13.5)$ & $(5-51.9)$ & \\
\hline \multicolumn{5}{|l|}{ Occlusion grade } \\
\hline Complete & $5(56)$ & $4(57)$ & $9(56)$ & 1.00 \\
\hline Entry remnant & $0(0)$ & $1(14)$ & $1(6)$ & 0.44 \\
\hline Subtotal filling & $3(33)$ & $1(14)$ & $4(25)$ & 0.58 \\
\hline Total filling & $1(9)$ & $1(14)$ & $2(10)$ & 1.00 \\
\hline
\end{tabular}

Data are presented as $n(\%), n$ (range), or mean \pm SD (range). PED, Pipeline embolization device; DSA, digital subtraction angiography; VRD, vascular reconstruction device.

case (11\%), and balloon remodeling of the newly placed device in 5 cases (56\%). Two cases (28\%) developed intraprocedural thrombosis that resolved with abciximab. One case (9\%) required verapamil infusion for vasospasm. The average procedure time and radiation exposure were $59.1 \pm 31.9 \mathrm{~min}$ and 3,812 $\pm 2,550 \mathrm{mGy}$, respectively, which were significantly higher than re-FD cases (33.7 $\pm 16.2 \mathrm{~min}, p=0.02$, and 2,132 $\pm 1,061 \mathrm{mGy}, p=0.03$, respectively) (Table 2).

Angiographic follow-up was available for 16 cases (80\%), including 9 cases in the re-FD group (82\%), and 7 cases in the re-VRD group (78\%). There was no significant difference in angiographic outcomes between the two groups. In re-FD treatments, complete occlusion was $56 \%(n=5)$, with $33 \%(n=3)$ showing progressive partial occlusion (entry remnant or subtotal filling) at an average of $17.1 \pm 15.8$ months, while in re-VRD treatments, complete occlusion was $57 \%(n=4)$, with $29 \%(n=2)$ showing progressive partial occlusion at an average of $8.1 \pm 3.1$ months (Table 2 ).

Two clinical complications occurred (10\%), including 1 mortality (5\%). One patient (case 11) with a large mid-basilar fusiform aneurysm previously treated with an FD experienced a brain stem stroke shortly after stopping clopidogrel 4 years after PED retreatment. CT angiography showed lack of contrast opacification at the proximal end of the stent extending to 


\section{Interventional Neurology}

\begin{tabular}{l}
\hline Intervent Neurol 2018;7:359-369 \\
\hline DOI: 10.1159/000489018
\end{tabular} \begin{tabular}{l}
$\begin{array}{l}\text { ○ 2018 S. Karger AG, Basel } \\
\text { www.karger.com/ine }\end{array}$ \\
\hline
\end{tabular}

Bender et al.: Salvage Flow Diversion for Previously Stented Aneurysms

Table 3. Re-FD PED salvage therapy case summaries

\begin{tabular}{|c|c|c|c|c|c|c|c|c|c|c|c|c|}
\hline $\begin{array}{l}\text { Case } \\
\text { No. }\end{array}$ & History & $\begin{array}{l}\text { Size, } \\
\mathrm{mm}\end{array}$ & Location & Type & $\begin{array}{l}\text { Previous } \\
\text { Txs, } n\end{array}$ & $\begin{array}{l}\text { Previous } \\
\text { stent }\end{array}$ & $\begin{array}{l}\text { Interval } \\
\text { since lat- } \\
\text { est stent, } \\
\text { months }\end{array}$ & $\begin{array}{l}\text { PEDs } \\
\text { used, } \\
n\end{array}$ & $\begin{array}{l}\text { Clinical } \\
\text { follow-up, } \\
\text { months }\end{array}$ & $\begin{array}{l}\text { Time from } \\
\text { retreatment } \\
\text { to follow-up } \\
\text { DSA, months }\end{array}$ & $\begin{array}{l}\text { Occlusion } \\
\text { on latest } \\
\text { follow-up }\end{array}$ & $\begin{array}{l}\text { Compli- } \\
\text { cations }\end{array}$ \\
\hline 1 & Inc & 5 & ICA, ophthalmic & Sac & 1 & PED & 42.6 & 1 & 17.9 & 5.7 & subtotal filling & no \\
\hline 2 & h/o SAH & 11 & ICA, PCoA & Sac & 3 & PED & 29.7 & 1 & 11.7 & 11.7 & complete & no \\
\hline 3 & diplopia & 18 & ICA, cavernous & Sac & 1 & PED & 27.2 & 1 & 17.3 & 17.3 & complete & no \\
\hline 4 & Inc & 5 & ICA, paraophthalmic & Sac & 1 & PED & 22.4 & 1 & 0.5 & - & - & no \\
\hline 5 & Inc & 3 & ICA, ophthalmic & Sac & 1 & PED & 15.4 & 1 & 8.5 & - & - & no \\
\hline 6 & Inc & 8 & ICA, ophthalmic & Sac & 1 & PED & 14.5 & 1 & 35.2 & 33.6 & $\begin{array}{l}\text { subtotal } \\
\text { filling }\end{array}$ & no \\
\hline 7 & Inc & 3 & ICA, PCoA & Sac & 1 & PED & 12.9 & 1 & 24.0 & 13.3 & complete & no \\
\hline 8 & Inc & 22 & vertebral, PICA & Sac & 3 & PED & 12.9 & 1 & 49.9 & 5.0 & total filling & no \\
\hline 9 & Inc & 9 & ICA, supraclinoid & Sac & 1 & PED & 10.3 & 1 & 10.1 & 6.6 & complete & no \\
\hline 10 & Inc & 22 & vertebral, PICA & Sac & 4 & PED & 8.3 & 1 & 41.5 & 8.3 & complete & \\
\hline 11 & TIA & 21 & basilar, mid-basilar & Fus & 1 & PED & 3.2 & 1 & 51.9 & 51.9 & subtotal filling & $\begin{array}{l}\text { delayed } \\
\text { brainstem } \\
\text { stroke, } \\
\text { mortality }\end{array}$ \\
\hline
\end{tabular}

FD, flow diverter; PED, Pipeline embolization device; DSA, digital subtraction angiography; ICA, internal carotid artery; PCoA, posterior communicating artery; PICA, posterior inferior cerebellar artery; Inc, incidental; h/o SAH, history of subarachnoid hemorrhage; Sac, saccular; Fus, fusiform.

Table 4. Re-VRD PED salvage therapy case summaries

\begin{tabular}{|c|c|c|c|c|c|c|c|c|c|c|c|c|}
\hline $\begin{array}{l}\text { Case } \\
\text { No. }\end{array}$ & History & $\begin{array}{l}\text { Size, } \\
\mathrm{mm}\end{array}$ & Location & Type & $\begin{array}{l}\text { Previous } \\
\text { Txs, } n\end{array}$ & $\begin{array}{l}\text { Previous } \\
\text { stent }\end{array}$ & $\begin{array}{l}\text { Interval } \\
\text { since lat- } \\
\text { est stent, } \\
\text { months }\end{array}$ & $\begin{array}{l}\text { PEDs } \\
\text { used, } \\
n\end{array}$ & $\begin{array}{l}\text { Clinical } \\
\text { follow-up, } \\
\text { months }\end{array}$ & $\begin{array}{l}\text { Time from } \\
\text { retreatment } \\
\text { to follow-up } \\
\text { DSA, months }\end{array}$ & $\begin{array}{l}\text { Occlusion } \\
\text { on latest } \\
\text { follow-up }\end{array}$ & $\begin{array}{l}\text { Compli- } \\
\text { cations }\end{array}$ \\
\hline 12 & diplopia & 20 & $\begin{array}{l}\text { ICA, } \\
\text { cavernous }\end{array}$ & Sac & 1 & $\begin{array}{l}\text { neuroform } \\
\text { stent-coil }\end{array}$ & - & 3 & 13.5 & 13.5 & complete & no \\
\hline 13 & trauma & 18 & $\begin{array}{l}\text { ICA, } \\
\text { cavernous }\end{array}$ & Diss & 1 & $\begin{array}{l}\text { wall-stent, } \\
\text { coil }\end{array}$ & 155.2 & 3 & 14.0 & 5.8 & entry remnant & no \\
\hline 14 & h/o SAH & 12 & vertebral, V4 & Diss & 1 & $\begin{array}{l}\text { coronary } \\
\text { stent }\end{array}$ & 128.2 & 1 & 10.4 & 7.3 & total filling & no \\
\hline 15 & $\begin{array}{l}\text { pupillary } \\
\text { dilatation, } \\
\text { ptosis \& } \\
\text { proptosis }\end{array}$ & 25 & $\begin{array}{l}\text { ICA, } \\
\text { cavernous }\end{array}$ & Sac & 1 & $\begin{array}{l}\text { neuroform } \\
\text { stent-coil }\end{array}$ & 116.5 & 2 & 0.6 & - & - & no \\
\hline 16 & Inc & 4 & $\begin{array}{l}\text { ICA, } \\
\text { ophthalmic }\end{array}$ & Sac & 1 & $\begin{array}{l}\text { neuroform } \\
\text { stent-coil }\end{array}$ & 110.1 & 1 & 9.0 & - & - & no \\
\hline 17 & Inc & 10 & $\begin{array}{l}\text { ICA, } \\
\text { supraclinoid }\end{array}$ & Sac & 2 & $\begin{array}{l}\text { neuroform } \\
\text { stent-coil }\end{array}$ & 103.4 & 3 & 13.8 & 7.1 & complete & no \\
\hline 18 & h/o SAH & 17 & $\begin{array}{l}\text { ICA, } \\
\text { ophthalmic }\end{array}$ & Sac & 3 & $\begin{array}{l}\text { enterprise } \\
\text { stent-coil }\end{array}$ & 45.2 & 1 & 11.2 & 11.2 & complete & $\begin{array}{l}\text { asymp- } \\
\text { tomatic } \\
\text { proximal } \\
\text { ICA } \\
\text { occlusion }\end{array}$ \\
\hline 19 & Inc & 25 & vertebral, VBJ & Fus & 4 & $\begin{array}{l}\text { neuroform } \\
\text { stent, PED }\end{array}$ & 32.9 & 1 & 8.8 & 5.6 & subtotal filling & no \\
\hline 20 & h/o SAH & 12 & vertebral, V4 & Diss & 2 & $\begin{array}{l}\text { coronary } \\
\text { stent, PED }\end{array}$ & 8.3 & 2 & 6.0 & 6.0 & complete & no \\
\hline
\end{tabular}

VRD, vascular reconstruction device; PED, Pipeline embolization device; DSA, digital subtraction angiography; ICA, internal carotid artery; Inc, incidental; h/o $\mathrm{SAH}$, history of subarachnoid hemorrhage; Sac, saccular; Fus, fusiform; Diss, dissecting.

the visualized vertebral artery, suggestive of in-stent thrombosis. The patient ultimately expired (Table 3). One patient (case 18) who underwent PED for recurrence after VRD stent coiling of a large ophthalmic-ICA aneurysm had asymptomatic proximal ICA occlusion on follow-up angiography (Table 4). Clinical follow-up was available for all patients for an average of 17.8 months ( \pm 15.1 months, range $0.5-51.9$ months). 


\section{Discussion}

This is a series of 20 patients with recurrent aneurysms successfully treated with PED in the presence of preexisting stents, both flow diverters and VRDs. Cases with in-dwelling VRD stents present additional technical challenges, as evident from the greater number of devices used, longer procedural time, higher radiation exposure, and balloon angioplasty rate. Salvage FD offers a good chance of occlusion (56\% complete occlusion at on average 13-month followup angiography) with acceptable complication rates.

Safety and effectiveness outcomes in this series confirm reports from a limited literature on the topic of FD as a salvage treatment following failed stent-coiling. Heiferman et al. [8] reported 25 such cases, of which $76 \%$ showed an improvement in Raymond grade at 12 -month follow-up angiogram, and 38\% showed complete occlusion. There were 3 major clinical complications $(12 \%)$, including carotid-cavernous fistula recognized and treated with liquid embolic agent during the embolization procedure, 1 postprocedural ICH resulting in dense hemiparesis with eventual recovery, and 1 delayed transient ischemic attack after clopidogrel discontinuation that resolved after resumption of antiplatelet therapy. Daou et al. [9] reported 21 cases of PED retreatment for previously stent-coiled aneurysms. Complete occlusion rate was $56 \%$ at an average of 10 months. There were 3 major clinical complications (14\%), including a posterior cerebral artery infarct, an ophthalmic artery embolus causing visual impairments, and an intracerebral hemorrhage leading to mortality (5\%). Fischer et al. [7] reported 30 cases of PED treatment for stent-coiling failure. Complete occlusion rate was $65 \%$ at an average of 10 months. Major complications were reported in 4 cases $(13 \%)$, including 2 intracerebral hemorrhages and 2 ischemic infarcts, one of which occurred when clopidogrel was stopped 8 weeks after retreatment. One death was reported (3\%). The present series includes 9 cases that were previously treated with stent coiling. Complete occlusion was observed in $57 \%$ at an average follow-up interval of 8 months, which is in the middle of the range of previous studies (38-65\%). The major complication rate $(13 \%)$ was also similar to previous studies (12-14\%).

There is limited literature on the efficacy and safety of PED retreatment of aneurysms previously treated with FD. This is likely because PED retreatment of persistent aneurysms is a more accepted practice, and tends not to be highlighted in larger series. For example, Fisher et al. [7] reported 8 PED retreatments (9\%) in a series of 101 PED cases; Park et al. [16] reported 9 PED retreatments (7\%) in a series of 133 PED cases; and, Lin et al. [17] reported 13 PED retreatments (13\%) in a series of 104 PED cases. These authors did not separately report complication rates and occlusion outcomes for re-FD cases, although the challenges others have encountered suggest this practice warrants independent consideration. Chiu et al. [18] reported 3 PED retreatments, 1 due to proximal migration of the device, with an occlusion rate of $33 \%$ at an average of 18 months. One of these patients (33\%) died secondary to in-stent thrombosis after clopidogrel was stopped 13 months after retreatment. Dornbos et al. [19] reported 2 retreatments of previously flow-diverted aneurysms with residual filling. One case (50\%) developed asymptomatic ICA occlusion at 6-month digital subtraction angiography (DSA), while complete aneurysm occlusion was achieved in the other case at 17 months (50\%). In the PUFS trial, 4 aneurysms with residual filling underwent PED retreatment, with complete occlusion rate of $50 \%$ and no reported complication [4]. The present series shows a $9 \%$ major complication rate and $56 \%$ complete occlusion at 17 months following re-FD, both numerically better than the limited available historical controls.

The technical challenge of a salvage FD case revolves around the indwelling stent, which poses an obstacle both to initial navigation and to device deployment. Given the large cell size and the propensity of the proximal tines to be "proud" at the parent vessel wall, it can be 
difficult to stay in the center channel or "true lumen" while navigating across an indwelling VRD. A flow diverter deployed through a cell in an indwelling VRD will initially appear to have restricted opening [8]. Attempts to open further with balloon angioplasty can lead to disastrous consequences: Gentric et al. [20] reported a case of an attempted SILK flow diverter treatment for persistence of a previously Y-stent coiled MCA bifurcation aneurysm in which balloon angioplasty of the incompletely opened proximal device ruptured the vessel. Autopsy later revealed the PED was deployed through the cell of an indwelling Solitaire stent. In addition to hypervigilance for any catching of the wire while crossing the indwelling stent, techniques that can be used to ensure deployment within the lumen of the parent vessel include: crossing with a J-tip wire, compliant balloon inflation following crossing, and visualization on DynaCT after crossing. Crossing an indwelling VRD is more difficult when the proximal end/stent tines are located in a vessel bend, such as the anterior genu. Conversely, crossing is facilitated when the proximal VRD device/stent tines are located in a straight segment, such as the horizontal segment of the cavernous ICA.

The indwelling stent also creates challenges during FD deployment. For primary FD treatments, we use a "drag and drop" technique, where the device is initially opened distal to the aneurysm and dragged back into position, a process that promotes opening. Such a strategy cannot be pursued in salvage treatments, as others have noted, given the risk of catching on the distal end of the indwelling device and anchoring the device to be implanted, leading to stretching and incomplete opening of the device [8, 21]. In salvage cases, we deploy the FD directly in its final location and rely more on balloon angioplasty for device opening and apposition. The rate of balloon angioplasty in salvage cases was $40 \%$ as compared with $13 \%$ in all anterior circulation PED cases [22]. Chalouhi et al. [21] reported a similar postdeployment angioplasty rate (50\%) for FD treatment of VRD-stented cases.

A common mechanism of aneurysm persistence after FD is malapposition between the stent and vessel wall, which allows blood flow to insinuate between the stent and vessel, continuing to fill the aneurysm, a so-called "endoleak" [23]. The risk of endoleak is greater in salvage FD cases given how a poorly endothelialized preexisting stent may prevent contact between the newly placed flow diverter and vessel endothelium. This is why we seek, whenever possible, to cover the preexisting stent both proximally and distally with the new FD in salvage cases (Fig. 1). This may be less important in re-FD cases, which are more likely to offer a regular, partially endothelialized surface across which salvage treatment serves to increase metal coverage, than re-VRD cases, which are more irregular. The number of patients in the present study is too low to test the importance of achieving proximal and distal coverage: in the $5 / 8$ re-FD cases that were completely occluded on follow-up DSA, $80 \%$ had proximal and $80 \%$ had distal coverage; in the $4 / 7$ re-VRD that were completely occluded on follow-up DSA, all had proximal coverage and $75 \%$ had distal coverage. Other authors have advocated for an approach similar to ours, emphasizing in particular the need for proximal coverage of the indwelling stent $[8,21]$.

Following successful salvage PED, heightened thrombogenicity of the multi-stent construct is a concern at every follow-up time point. We observed intraprocedural platelet accumulation along the stent construct in $2 / 9$ re-VRD cases $(22 \%, 10 \%$ overall in salvage cases), which both resolved without symptoms after abciximab administration. Fischer et al. [7] reported a patient with large dissecting MCA aneurysm initially treated with coaxial Enterprise and Solitaire stents and subsequently treated with 2 PED who developed severe headaches postprocedurally and was found to have aneurysm thrombosis on DSA and scattered MCA territory diffusion restriction on MRI. Asymptomatic parent vessel occlusion has been observed on routine follow-up DSA in the present series and by others [19], although it is unclear whether this is related to the stent construct, proximal dissection, or otherwise. Reports abound of ischemic symptoms following the cessation of dual antiplatelet therapy, 

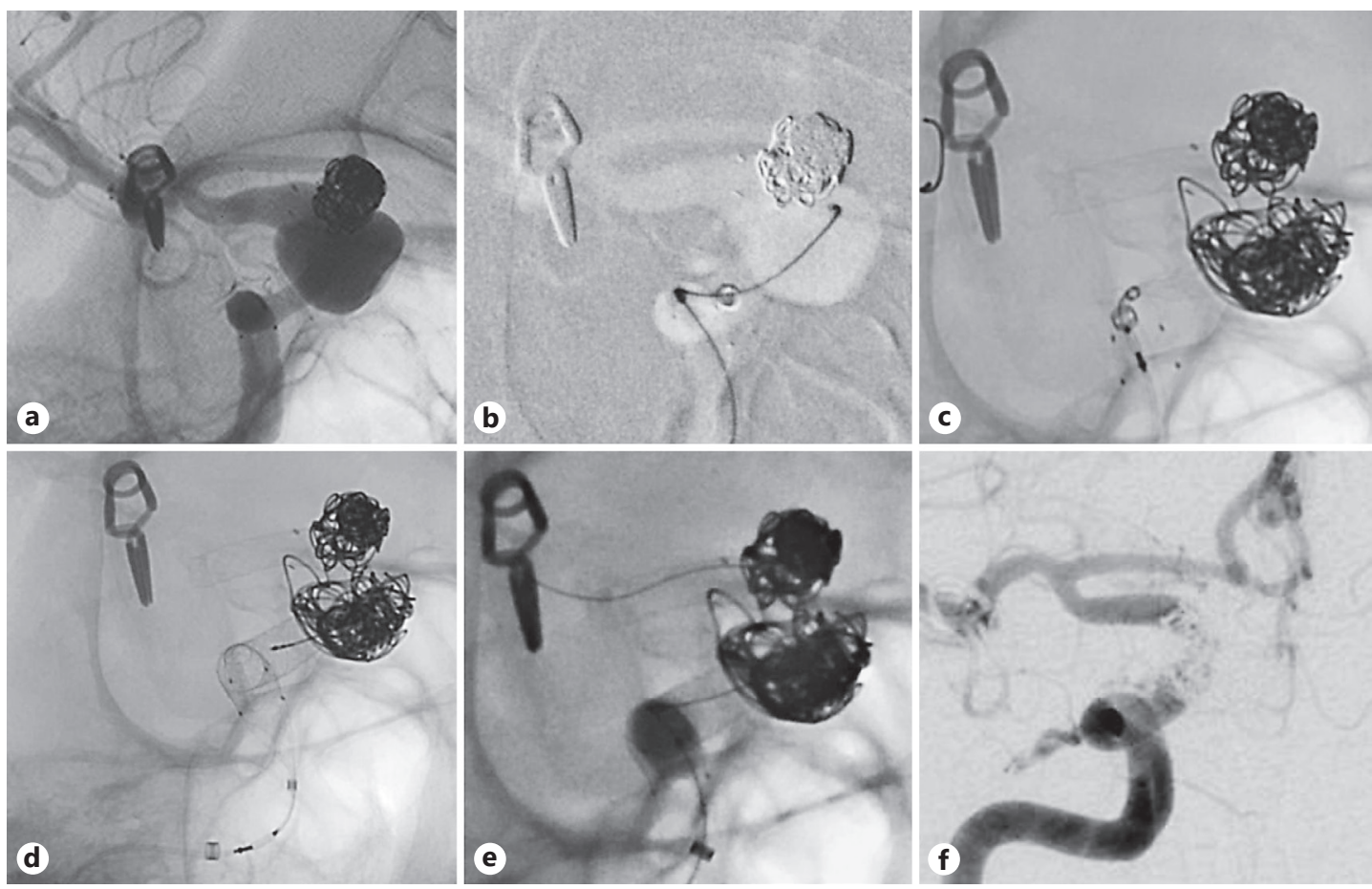

Fig. 1. Case 17: a quinquagenarian female with a history of supraclinoid R ICA aneurysm previously treated with Neuroform stent-assisted coiling found to have (a) enlarging residual on routine follow-up DSA (b) underwent single stage coiling (c) and placement of 3 PED devices deployed directly in their final location covering the distal and (d) proximal ends of the indwelling construct with (e) balloon angioplasty used to improve opening and apposition. $\mathbf{f}$ Complete aneurysm occlusion at 6-month follow-up DSA.

Fig. 2. Case 9: a quadragenarian female with a 9-mm supraclinoid ICA aneurysm (a) initially treated with single PED in the ICA who subsequently developed (b) device foreshortening with associated aneurysm persistence and underwent (c) re-PED with the construct extending into the MCA. d Complete aneurysm occlusion at 6-month follow-up DSA.
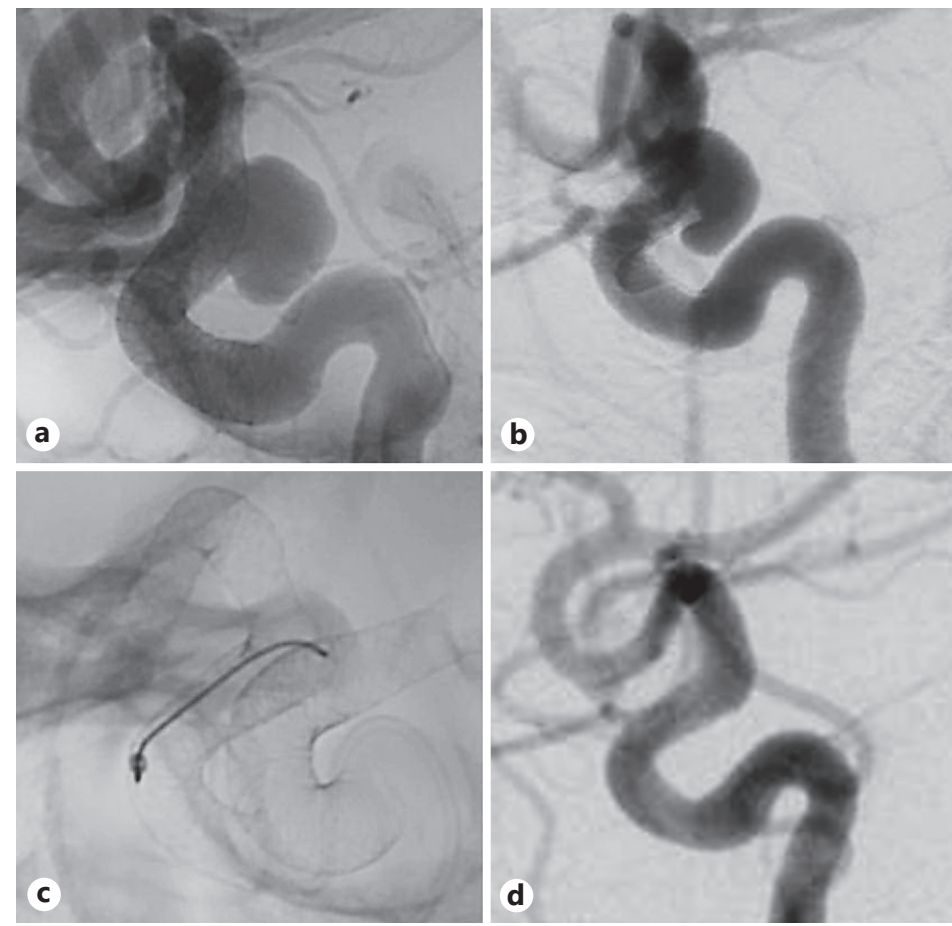
whether at 6 weeks after procedure [7], 18 months [18], or 4 years, as in our case. We keep these patients on systemic heparin for the night after surgery to temporize any developing thrombus in the acute postprocedural period. Fischer et al. [17] observed that placing one stent inside another will always delay the endothelialization process and that extended or lifetime DAT should be considered for these patients.

Although commonly used as an endpoint in trials of endovascular aneurysm treatment, studies have shown low rates of interobserver agreement about the need for retreatment [24]. Retreatment of previously VRD aneurysms typically addresses recanalization or recurrence compared to end-embolization DSA. Given the decay in occlusion outcomes over time with stent coiling, the interval between initial treatment and re-VRD is longer than re-FD (88 months in our series and 20-40 months in the literature [8,9]. Retreatment is reserved for recanalized stent-coiled aneurysms with a history of prior rupture or progressive symptoms, typically from mass effect. By contrast, retreatment of previously FD aneurysms is commonly for persistence or failure to occlude and occasionally for device foreshortening (Fig. 2). Given the perceived ease of re-FD, which did require less procedural time in this study, some authors have a low threshold for retreatment. Park et al. [16] re-treated any aneurysms showing residual filling at 6-month DSA, which amounted to 8/68 (12\%) single-modality FD cases. Since occlusion outcomes continue to accrue for up to 5 years after PED placement [4], we wait to complete DAT tapering and have performed re-FD cases at an average of 18 months after the first procedure.

Alternative treatments must be considered before proceeding with FD of an aneurysm with an indwelling stent. Pipeline embolization within a VRD is contraindicated per the FDA, but is sometimes the best option. Previously stent-coiled aneurysms can be re-coiled, but reports on long-term durability are limited. Re-accessing the aneurysm dome through a poorly visualized and partially endothelialized stent may pose increased risk of intraprocedural aneurysm rupture. As a result, multiple telescoping VRD was a common mode of re-treating recurrent stent-coiled aneurysms prior to the introduction of FD [21]. Salvage FD may not be appropriate in perforator-rich locations where excess metal and incomplete stent wall apposition can jeopardize perforating vessels (e.g., the basilar apex) or when there is no landing zone to achieve proximal coverage of the existing stent (e.g., an anterior communicating artery aneurysm in which the ACA stent abuts the ICA termination). FD sacrifices access to the aneurysm dome, so coiling is not an option for recurrence of previously FD aneurysms. Surgical clipping has been reported for thrombosed but enlarging aneurysms with associated mass effect after prior stenting [25]. There are multiple challenges associated with this scenario: parent vessel rigidity secondary to the stent limits the ability to achieve proximal control, and antiplatelet therapy may need to be continued through surgery to prevent stent and parent vessel thrombosis.

This series is limited by its small, retrospective, observational nature. Outcome ascertainment can be incomplete in series with limited follow-up: in the present series, follow-up DSA was available for $80 \%$ of patients, and clinical follow-up averaged 18 months, including 2 patients who were seen and doing well 2 weeks after embolization but had not yet reached the 6-month DSA milestone. Comparisons cannot be drawn with the general FD population since aneurysms represented here are larger and have more complex morphologies. Published historical controls represent a fraction of the experience to date with salvage FD, and comparison with these is limited by very small numbers. Retreatment criteria are subjective without a standard adopted across institutions. 


\section{Conclusions}

Salvage FD can be used to address aneurysm recurrence after stent coiling or persistence after initial FD with acceptable safety and effectiveness outcomes.

\section{Disclosure Statement}

Alexander L. Coon is a consultant and proctor for Medtronic, Stryker, and Microvention. Geoffrey P. Colby is a consultant for Microvention and Codman. Li-Mei Lin is a proctor for Medtronic.

\section{References}

1 Akpek S, Arat A, Morsi H, Klucznick RP, Strother CM, Mawad ME: Self-expandable stent-assisted coiling of wide-necked intracranial aneurysms: a single-center experience. AJNR Am J Neuroradiol 2005;26:12231231.

-2 Colby GP, Paul AR, Radvany MG, Gandhi D, Gailloud P, Huang J, et al: A single center comparison of coiling versus stent assisted coiling in 90 consecutive paraophthalmic region aneurysms. J Neurointerv Surg 2011;4: 116-120.

3 Becske T, Kallmes DF, Saatci I, McDougall CG, Szikora I, Lanzino G, et al: Pipeline for uncoilable or failed aneurysms: results from a multicenter clinical trial. Radiology 2013;267:858-868.

- 4 Becske T, Brinjikji W, Potts MB, Kallmes DF, Shapiro M, Moran CJ, et al: Long-term clinical and angiographic outcomes following Pipeline embolization device treatment of complex internal carotid artery aneurysms: five-year results of the Pipeline for Uncoilable or Failed Aneurysms Trial. Neurosurgery 2017;80:40-48.

-5 Bender M, Colby GP, Lin L-M, Jiang B, Westbroek EM, Campos JK, et al: Predictors of cerebral aneurysm persistence and occlusion after flow diversion: a single-institution series of 445 cases with angiographic follow-up. J Neurosurg DOI: 10.3171/2017.11.JNS171738.

-6 Hong Y, Wang Y-J, Deng Z, Wu Q, Zhang J-M: Stent-assisted coiling versus coiling in treatment of intracranial aneurysm: a systematic review and meta-analysis. PLoS One 2014;9:e82311.

-7 Fischer S, Vajda Z, Aguilar Perez M, Schmid E, Hopf N, Bäzner H, et al: Pipeline embolization device (PED) for neurovascular reconstruction: initial experience in the treatment of 101 intracranial aneurysms and dissections. Neuroradiology 2011;54:369-382.

-8 Heiferman DM, Billingsley JT, Kasliwal MK, Johnson AK, Keigher KM, Frudit ME, et al: Use of flow-diverting stents as salvage treatment following failed stent-assisted embolization of intracranial aneurysms. J Neurointerv Surg 2015;8:692-695.

-9 Daou B, Starke RM, Chalouhi N, Tjoumakaris S, Hasan D, Khoury J, et al: Pipeline embolization device in the treatment of recurrent previously stented cerebral aneurysms. AJNR Am J Neuroradiol 2015;37:849-855.

-10 Colby GP, Lin L-M, Gomez JF, Paul AR, Huang J, Tamargo RJ, et al: Immediate procedural outcomes in 35 consecutive pipeline embolization cases: a single-center, single-user experience. J Neurointerv Surg 2013;5:237246.

11 Colby GP, Lin L-M, Caplan JM, Jiang B, Huang J, Tamargo RJ, et al: Immediate procedural outcomes in 44 consecutive Pipeline Flex cases: the first North American single-center series. J Neurointerv Surg 2016;8:702-709.

12 Lin L-M, Bender MT, Colby GP, Beaty NB, Jiang B, Campos JK, et al: Use of a next-generation multi-durometer long guide sheath for triaxial access in flow diversion: experience in 95 consecutive cases. J Neurointerv Surg 2018;10:137-142.

13 Colby GP, Lin L-M, Xu R, Beaty N, Bender MT, Jiang B, et al: Utilization of a novel, multi-durometer intracranial distal access catheter: nuances and experience in 110 consecutive cases of aneurysm flow diversion. Interv Neurol 2017;6:90-104.

14 Lin L-M, Colby GP, Bender MT, Xu R, Huang J, Tamargo RJ, et al: Use of the 0.027-inch VIA microcatheter for delivery of Pipeline Flex: a technical note. J Neurointerv Surg 2017;9:689-693.

$\checkmark 15$ O’Kelly CJ, Krings T, Fiorella D, Marotta TR: A novel grading scale for the angiographic assessment of intracranial aneurysms treated using flow diverting stents. Interv Neuroradiol 2010;16:133-137.

-16 Park MS, Nanaszko M, Sanborn MR, Moon K, Albuquerque FC, McDougall CG: Re-treatment rates after treatment with the Pipeline embolization device alone versus pipeline and coil embolization of cerebral aneurysms: a single-center experience. J Neurosurg 2015;125:137-144.

17 Lin N, Brouillard AM, Krishna C, Mokin M, Natarajan SK, Sonig A, et al: Use of coils in conjunction with the Pipeline embolization device for treatment of intracranial aneurysms. Neurosurgery 2014;76:142-149.

18 Chiu AHY, Cheung AK, Wenderoth JD, De Villiers L, Rice H, Phatouros CC, et al: Long-term follow-up results following elective treatment of unruptured intracranial aneurysms with the Pipeline embolization device. Am J Neuroradiol 2015;36:1728-1734. 


\section{Interventional Neurology}

Bender et al.: Salvage Flow Diversion for Previously Stented Aneurysms

19 Dornbos D, Karras CL, Wenger N, Priddy B, Youssef P, Nimjee SM, et al: Pipeline embolization device for recurrence of previously treated aneurysms. Neurosurg Focus 2017;42:E8.

-20 Gentric J-C, Fahed R, Darsaut TE, Salazkin I, Roy D, Raymond J: Fatal arterial rupture during angioplasty of a flow diverter in a recurrent, previously Y-stented giant MCA bifurcation aneurysm. Interv Neuroradiol 2016; 22:278-286.

-21 Chalouhi N, Chitale R, Starke RM, Jabbour P, Tjoumakaris S, Dumont AS, et al: Treatment of recurrent intracranial aneurysms with the Pipeline embolization device. J Neurointerv Surg 2013;6:19-23.

-22 Colby GP, Bender MT, Lin L-M, Beaty N, Caplan JM, Jiang B, et al: Declining complication rates with flow diversion of anterior circulation aneurysms after introduction of the Pipeline Flex: analysis of a single-institution series of 568 cases. J Neurosurg DOI: 10.3171/2017.7.JNS171289.

-23 Shapiro M, Becske T, Nelson PK: Learning from failure: persistence of aneurysms following pipeline embolization. J Neurosurg 2016;126:578-585.

24 Daugherty WP, Rad AE, White JB, Meyers PM, Lanzino GL, Cloft HJ, et al: Observer agreement regarding the necessity of retreatment of previously coiled recurrent cerebral aneurysms. AJNR Am J Neuroradiol 2011;32: 566-569.

25 Pacetti M, Mosimann PJ, Zerlauth J-B, Puccinelli F, Levivier M, Daniel RT: Letter to the Editor. Clipping after Pipeline embolization device placement for a thrombosed ACoA aneurysm. J Neurosurg 2017;127:958. 